\title{
TRÁFICO DE PESSOAS, A ESCRAVIDÃO MODERNA. UMA LEITURA A PARTIR DO PENSAMENTO DE HENRIQUE DUSSEL
}

Ir. Jucelaine Aparecida Soares, mscs*

Esta reflexão aborda o problema do tráfico de pessoas com base na ética da vida. O tráfico humano, frequentemente, configura-se como um tipo de escravidão e, assim sendo, como violação da dignidade do 'ser humano'. A seguir analisaremos essa questão a partir do pensamento do filósofo argentino Henrique Dussel, principalmente no que diz respeito ao encobrimento do outro, à ética da libertação e à ética da vida enquanto conteúdo ou material. ${ }^{1}$

De princípio queremos explicitar que o tráfico de pessoas acontece, frequentemente, quando o indivíduo deseja emigrar, mas não possui dinheiro suficiente para custear toda a operação de travessia. Assim sendo, oferece em garantia sua força de trabalho, ficando estabelecida entre o aliciador e o migrante uma relação de exploração em razão da dívida contraída. Trata-se, portanto, na visão de Dussel, de uma forma de alienação, fruto da ideologia do mercado neoliberal, no qual a pessoa tenta sobreviver buscando uma vida digna, da qual foi excluída por um sistema vitimário e egocêntrico.

Desta alienação decorre o assim chamado trabalho análogo à escravidão, que está presente na sociedade de hoje, mas que tem suas raízes fincadas na América Latina desde que o homem se estabeleceu como senhor "colono", o que provocou a difusão da desigualdade social e da vulnerabilidade social.

Os colonizadores, nas Américas, "descobriram" as terras que já eram habitadas pelos índios. Na realidade, o que ocorre é um "encobrimento do outro" e o surgimento do paradigma da modernidade: o ego do homem

\footnotetext{
Missionária Scalabriniana, trabalha na área de Educação em Santo André/Brasil.

1 “Em alemão, Material (com 'a') significa 'material', como "conteúdo (Inhalt)", oposto ao material formal (cf. DUSSEL, Enrique. Ética da libertação: na idade da globalização e da exclusão. Petrópolis: Vozes, 2000, p. 635-636).
} 
europeu vitimiza e encobre o outro para realizar a "si mesmo", como argumenta Dussel: "a América não é descoberta como algo que resiste distinta, como o Outro, mas como matéria onde é projetado 'o si-mesmo'. Então não é o 'aparecimento do Outro', mas a 'projeção do si-mesmo': encobrimento". ${ }^{2}$

De acordo com a concepção dusseliana o continente Latino-Americano foi e é fortemente marcado pela exploração. O Brasil, por exemplo, desde a colonização passou por sucessivas formas de exploração. Os índios que aqui habitavam não foram respeitados como povos e suas culturas foram destruídas ou marginalizadas. Num primeiro momento, houve um processo colonizador em busca de áreas para extração de recursos naturais a fim de alimentar o mercado europeu. Em virtude da necessidade de realização dos trabalhos mais bruscos, manuais, braçais, os colonizadores, diante da receptividade dos índios, passaram a se apoderar da sua força de trabalho. Com a chegada dos jesuítas, a apoderação do trabalho dos índios pelos portugueses foi rechaçada, restando como alternativa - utilizada pela maioria dos Estados europeus colonialistas - a intensificação na utilização de mão-de-obra africana.

Nesse contexto, muitos africanos, que na época eram vistos apenas como res vocale (coisa que falava), foram trazidos como escravos ao Brasil, através dos navios negreiros, e eram vendidos aos "Senhores de Engenho", passando a ser explorados, subjugados aos desejos e desígnios destes:

A "conquista" é um processo militar, prático, violento que inclui dialeticamente o Outro como o "si-mesmo". O outro, em sua distinção, é negado como Outro é sujeitado, subsumido, alienado a se incorporar à Totalidade dominadora como coisa, como instrumento, como oprimido, como "encomendado, como "assalariado" ..., ou como africano e escravo... ${ }^{3}$

O "eu colonizado" é coisificado e incorporado à "Totalidade dominadora" de um novo sistema econômico, como mão-de-obra escrava ou barata. A fonte principal da crítica ética de Dussel está na negação da corporeidade da vítima, no corpo que sente fome e frio, que é explorado na reprodução do capital. O sujeito ético dusseliano assume aqui uma forma ampla, pois, aparece primeiramente como conteúdo material, pulsional.

O pobre não tem lugar, não tem vez, porque dentro "Totalidade dominadora" não há espaço, por ser ele uma negatividade; é um nãoser às margens da totalidade. O sujeito corpóreo é dominado e explorado constantemente, a fim de exercer forçosamente um trabalho torturante e degradante, correlacionando à falta de prazer, numa perspectiva que Marx

DUSSEL, Henrique. 1492 - O encobrimento do outro. Petrópolis: Vozes, 1993, p. 35.

Ibidem, p. 44. 
chama de trabalho estranhado, forma como se dá a alienação em que o capital é uma relação social de produção e o trabalho entra como fator central. Mas, uma centralidade que subverte a potencialidade do trabalho como trabalho concreto, subsumindo-o, ao contrário, à sua dimensão de valor de uso para o capital. O sujeito surge diante do capitalismo apenas como a personificação do trabalho, como se esse existisse apenas para o trabalho. Estas são as condições de vida das vítimas do tráfico de pessoas e aqui Dussel propõe uma ética da libertação das vítimas do sistema-mundo, libertação que pode ser cotidianamente conquistada. Pois, o filósofo afirma que a sua ética é cotidiana, uma ética da vida, que se constrói num pensamento filosófico anti-hegemônico, libertando-se, por conseguinte, da falácia reducionista do egocentrismo do paradigma europeu e afirmando a alteridade negada das vítimas.

A dignidade da pessoa e os valores sociais do trabalho são severamente desrespeitados. A ética de Dussel parte da tomada de consciência éticocrítica da "negatividade" das vítimas do sistema vigente, que se concretiza na negação da corporeidade expressa no sofrimento. Trata-se de superar a consciência ingênua e perceber que o sistema vigente deve ser criticado e transformado por produzir vítimas e, portanto, não desenvolver a vida: "No capitalismo se acumula riqueza objetiva... em mãos de poucos, e aumenta a 'pobreza' da maioria..." ${ }^{4}$.

No passado, os escravos eram capturados por grupos inimigos e vendidos como mercadoria. Hoje, o tráfico de pessoas é uma realidade desumana, irracional, mas muito lucrativa. Desenvolve-se à margem da sociedade. No Brasil o tráfico de pessoas avança cada vez mais. Famílias inteiras em busca de sustento estão à mercê de pessoas mal intencionadas, que não vêem o outro como ser humano. Este, por sua vez, fica alienado, preso àquilo que o mundo Ihe ofereceu e, por diferentes razões - sobretudo políticas -, sem a oportunidade de buscar conhecimento. Nele foi implantada a ideia de que a vida que the fora dada era esta, tinha que ser assim, que isto estava determinado por Deus. Estas ideias impedem de enxergar como os poderes políticos e econômicos causam e sustentam desigualdade entre os seres humanos.

É nessa via que Henrique Dussel trata de uma ética universal, pois esse considerado "outro" desde a modernidade é o oprimido, o índio que não pôde ser igual ao europeu. Não pode porque lhe foi tirado o direito da vida, como diz Dussel. Entendamos um pouco a questão dusseliana: os europeus conquistadores coagiram os povos latinos americanos com base numa racionalidade que para Dussel é, na realidade, uma irracionalidade que destruiu, alterou ou marginalizou todos os costumes destes povos ao

4 Ibidem, p. 113. 
invés de respeitar sua cultura. Esses europeus empregaram aqui um regime de trabalho escravo, exploraram tudo o que puderam explorar: os índios, as riquezas naturais, a sexualidade das índias etc. A filosofia cartesiana tornou-se o paradigma cultural a ser imposto, sem respeito algum pela diversidade. A "periferia" tinha que se submeter à cosmovisão do "centro", dos "senhores".

Dessa forma, tudo o que não segue o modelo epistemológico de Descartes é considerado inferior, periférico, logo não é. Não sendo pode ser explorado. Para este ser que não é o que lhe resta é aceitar a alienação e ainda agradecer as migalhas que lhes são dadas ao invés de nada. É nesse sentido que Dussel com sua hermenêutica tenta nos mostrar essa irracionalidade, pois como:

Espanha e Portugal (...) foi a primeira região da Europa a ter a "experiência" originária de constituir o outro como dominado e sob o controle do conquistador, do domínio do centro sobre a periferia... sofremos globalmente desde nossa origem um processo constitutivo de "modernização" que depois se aplicará a Ásia e a África. ${ }^{5}$

Não obstante, esse modelo também está presente hoje. Ou seja, se perpetua o paradigma que favorece não a todos, mas aos poderosos, a uma classe social. O que mais vemos em nossa sociedade moderna é um ser humano se sobrepor ao outro. Embora, hoje existam leis que defendem a cada pessoa, elas não são aplicadas da mesma maneira para grupos sociais diferentes, pois se assim fosse não teríamos tanta miséria e fome, não só na América Latina, mas em todos os lugares do mundo.

No Brasil, a Constituição da República, no Art. 5o diz: “Todos são iguais perante a lei, sem distinção de qualquer natureza, garantindo-se aos brasileiros e aos estrangeiros residentes no País a inviolabilidade do direito à vida, à liberdade, à igualdade, à segurança e à propriedade..." ${ }^{\prime 6}$. A nossa questão é: por que isso não se aplica na prática?

Antes justificava assim a exploração:

Será sempre justo e conforme o direito natural que tais gentes (bárbaras) se submetam ao império dos príncipes e nações mais cultas e humanas, para que, pelas suas virtudes e pela a prudência das suas leis, abandonem a barbárie e se submetam a uma vida mais humana e ao culto da virtude. ${ }^{7}$

Sabemos que esse modelo justificativo foi reformulado a partir do pensamento de Descartes e com isso houve uma expansão do mecanicismo

Ibidem, p. 16.

6 CONSTITUIÇÃO DA REPÚBLICA DO BRASIL DE 1988. Art. 5ㅇ․

7 SANTOS, Boaventura de Sousa; MENESES, Maria Paula. Epistemologias do Sul. São Paulo: Cortez, 2006, p. 355. 
e do instrumentalismo, bem como uma aceleração na economia e no meio de vida das pessoas. Aceleração de um novo paradigma que evolui. Hoje, ao invés da ordem e progresso ditada, o que se vê é um progresso sem ordem, porque não se percebe mais o humano e sim o número, o valor adquirido pelo seu trabalho e até o custo desses para o capital. Quanto vale um humano hoje?

Dussel argumenta que: "A modernidade aparece quando a Europa se afirma como "centro" e uma história Mundial que inaugura, e por isso a "periferia" é a parte de sua própria definição". ${ }^{8}$

Estamos assim chegando ao âmago do pensamento do Dussel: a vida que foi e continua sendo encoberta. Desde que os conquistadores europeus chegaram nas Américas, a vida humana vale por aquilo que seu corpo pode produzir. Esse é o modelo implantando desde quando a modernidade se afirmou como "centro". Entendamos agora essa sociedade moderna de hoje.

Toda a expansão advinda da modernidade só deu continuidade a uma lógica que mantém os poderosos no "centro" e os trabalhadores na "periferia". Essa realidade está evidente em cada esquina das grandes cidades. O pobre é tratado com descaso pelo Estado. Esse descaso está nos hospitais, nas escolas que mecanizam mais ainda o ser humano ao invés de ensiná-lo a pensar. Está em cada esquina aonde tem um migrante sofrendo, enquanto as autoridades competentes nem ao menos sabem. Esses migrantes, muitas vezes, são trazidos juntamente com a sua ilusão e, de certa forma, uma coerção verbal. Uma promessa que não se cumpre e aliena o indivíduo por sua ingenuidade.

O que Dussel aponta com isso é exatamente a continuidade de um modelo irracional, que se mantém pelo egoísmo humano. Esse mesmo egoísmo hoje que aliena o ser humano de todas as formas veicula-se invisivelmente na sociedade. Uma sociedade moderna, consumista que acredita na falácia dos "centros", que ditam parâmetros para os homens até hoje. Assim se sustentam no poder: enquanto eles se tornam cada vez mais ricos, os pobres, embora gerem muita riqueza, ficam cada vez mais pobres e alienados ao sistema vigente - o capitalismo. Portanto, o que Dussel critica, na verdade, é o sistema capitalista globalizado, a hegemonia ideológica que gera exclusão material e discursiva da maioria de vítimas. Em suma, a globalização oculta a sua crise, que é a exclusão ou opressão das vítimas resultante da dominação das mesmas. Daí a dialética globalização-exclusão, que tem como fator de maior visibilidade, no mundo atual, os fenômenos do tráfico de pessoas e do trabalho análogo à escravidão.

${ }^{8}$ DUSSEL, $1492 \ldots$, op. cit., p. 7. 